\title{
ATP Hydrolysis in Water - A Density Functional Study
}

\author{
J. Akola and R. O. Jones* \\ Institut für Festkörperforschung, Forschungszentrum Jülich, D-52425 Jülich, Germany
}

Received: June 2, 2003; In Final Form: August 11, 2003

\begin{abstract}
Adenosine $5^{\prime}$-triphosphate (ATP) is a basic energy carrier in cellular metabolism. As a high-energy intermediate, it provides a way to convert energy from one biochemical process to another via an environment-dependent hydrolysis reaction. Two paths for ATP hydrolysis in water with $\mathrm{Mg}^{2+}$ are studied here using the density functional method: an associative reaction involving a nucleophilic attack of one water molecule, and a dissociative reaction involving a scission of the terminal bridging $\mathrm{P}-\mathrm{O}$ bond. The latter has an activation energy of $35 \mathrm{kcal} / \mathrm{mol}$, where $25 \mathrm{kcal} / \mathrm{mol}$ can be assigned to the $\mathrm{P}-\mathrm{O}$ bond breaking and $10 \mathrm{kcal} / \mathrm{mol}$ to the artificial stability of $\mathrm{PO}_{3}{ }^{-}$resulting from the small size and the short time scale of the simulation. The path and energy barrier $(39 \mathrm{kcal} / \mathrm{mol})$ of the less-favorable associative reaction suggest that it is possible only under conditions where the lytic water is already deprotonated to $\mathrm{OH}^{-}$. The $\mathrm{Mg}$ cation elongates the terminal bridging $\mathrm{P}-\mathrm{O}$ bond when forming a bidentate chelate with the two terminal phosphates. Additional constrained displacements of $\mathrm{Mg}^{2+}$ with respect to the nearest phosphate oxygens show that a direct electrophilic attack of $\mathrm{Mg}$ toward a bridging $\mathrm{O}$ is possible.
\end{abstract}

\section{Introduction}

Many different nucleotides and their derivatives are present in mammalian cells, the most abundant being adenosine 5'-triphosphate ATP (Scheme 1), which exists in millimolar range concentrations. Nucleotides play critical and diverse roles in cellular metabolism as monomeric units of nucleic acids, allosteric effectors of metabolic pathways, activated intermediates for variety of reactions, components of coenzymes, and physiological mediators. ${ }^{1}$ ATP has a prominent role as a basic building block of energy metabolism, where it is a principal form of energy available to cells. It drives reactions as a phosphorylating agent, and is involved in muscle contraction (myosin, actin), ${ }^{2,3}$ active transport (kinases), ${ }^{2}$ protein folding (chaperones), ${ }^{4}$ and maintenance of ion gradients (ATP synthases).$^{5-7}$ It also serves as a phosphate donor for generation of other nucleotides, ${ }^{1}$ and under certain conditions even the adenosyl group of ATP is used for biosynthesis of cofactors. ${ }^{8}$

The traditional way to think of ATP energetics is to assign the terminal $\mathrm{P}-\mathrm{O}_{\mathrm{s}}$ bond $\left(\mathrm{O}_{\mathrm{s}}\right.$ denotes an anhydride oxygen) in the triphosphate tail of the molecule as an energy-rich bond that releases energy upon hydrolysis due to the Coulomb repulsion of products, resonance effects, and changes in protonation. George et al. ${ }^{9}$ have noted, however, that this does not consider the solvation energies of the components and the changes in entropy. Later studies have shown that the equilibrium constants $(K)$ for hydrolysis depend sensitively on the solvent composition, salt concentration (presence of $\mathrm{Mg}^{2+}$, ionic hardness), and acidity ( $\mathrm{pH})$ of the solution. ${ }^{10-13}$ The importance of the environment is underscored further by the observation ${ }^{5}$ that the energetically crucial step in the hydrolysis of ATP synthase is the binding of reaction constituents on the enzyme active site, not the hydrolysis reaction itself.

There is a wealth of experimental information concerning the protonation state, conformation, and metal-chelation of ATP. ${ }^{14-18}$ H-NMR experiments ${ }^{16,17}$ show that the molecule exists in water

*Corresponding author (e-mail: r.jones@fz-juelich.de).

\section{SCHEME 1: Deprotonated Form of ATP Molecule}

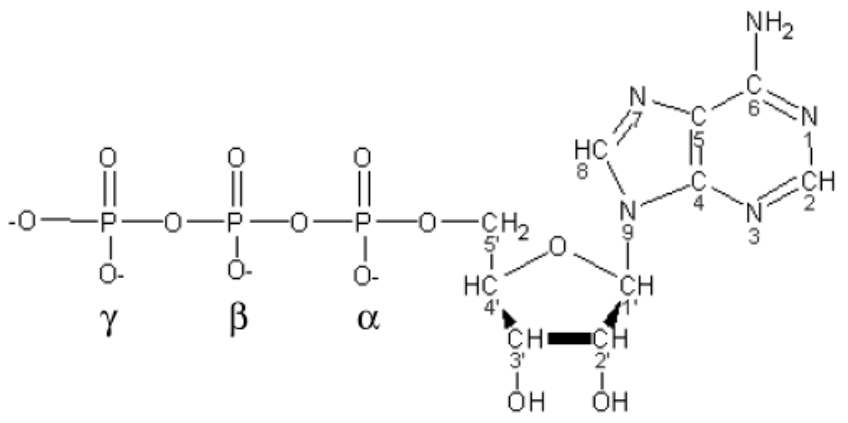

in a linear anti configuration, and the triphosphate tail is fully deprotonated under neutral conditions (Scheme 1), especially when complexed with $\mathrm{Mg}^{2+}$. Calorimetric measurements of $\operatorname{Mg}(\mathrm{ATP})^{2-}$ complexes $^{18}$ show that the enthalpy change is slightly positive on chelate formation between $\mathrm{Mg}^{2+}$ and phosphate oxygens, so that it is an entropy-driven process. Entropy is also responsible for the fact that $\mathrm{Mg}^{2+}$ binds to ATP more readily than to adenosine $5^{\prime}$-diphosphate (ADP). X-ray crystal structures have been reported on ATP salts, ${ }^{19-24}$ but no direct $\mathrm{Mg}(\mathrm{ATP})$ complexes are obtained due to the spontaneous nonenzymatic hydrolysis during crystallization. ${ }^{22} \mathrm{Na}_{2}$ (ATP) crystals with varying degrees of hydration ${ }^{19-24}$ all show characteristic triphosphate chain folding and base stacking of adenine groups. The interaction between $\mathrm{Mg}^{2+}$ and phosphate tail is evident from the $\mathrm{Mg}_{2} \mathrm{P}_{2} \mathrm{O}_{7}$ hexahydrate salt, ${ }^{22}$ where $\mathrm{Mg}^{2+}$ changes the properties of pyrophosphate significantly.

Several attempts have been made to model the break of the anhydride $\mathrm{P}-\mathrm{O}_{\mathrm{s}}-\mathrm{P}$ linkage and to understand the underlying mechanism. ${ }^{25-34}$ The approaches range from simple molecular orbital calculations ${ }^{25}$ to contemporary quantum mechanical calculations of the isolated active site of myosin. ${ }^{33}$ Gas-phase calculations of pyrophosphate hydrolysis ${ }^{28-31}$ indicate that there is no internal energy reservoir in the terminal $\mathrm{P}-\mathrm{O}_{\mathrm{s}}$ bond, i.e., the energy difference between the reactants and the products 
fluctuates around zero, depending of the protonation state (charge) of the reaction and the catalyst used. The reaction paths considered in the gas phase $\mathrm{e}^{28,30}$ are dissociative, where a metastable $\mathrm{PO}_{3}{ }^{-}$phosphate unit is formed prior to a nucleophilic attack of one water molecule. $\mathrm{Mg}^{2+}$ has a strong catalytic activity related to its ability to elongate one of the anhydride $\mathrm{P}-\mathrm{O}$ bonds, with an estimated reaction barrier of $13.5 \mathrm{kcal} /$ mol for a pyrophosphate dianion. ${ }^{30}$

In this article, we model the ATP hydrolysis reaction in an aqueous environment using density functional (DF) theory. We aim to shed light on the possible reaction mechanisms (and reaction coordinates) of hydrolysis and to study the properties of $\mathrm{Mg}(\mathrm{ATP})$ complexes in water. We know of no earlier theoretical studies of this problem. We consider two mechanisms - dissociative and associative - for the reaction

$$
\mathrm{Mg}(\mathrm{ATP})^{2-}+\mathrm{H}_{2} \mathrm{O} \rightleftharpoons \mathrm{Mg}(\mathrm{ADP})^{-}+\mathrm{P}_{i}^{-}
$$

where $\mathrm{P}_{i}^{-}$denotes either $\mathrm{H}_{2} \mathrm{PO}_{4}{ }^{-}$or $\mathrm{HPO}_{4}{ }^{2-}$ and a separated proton $\mathrm{H}^{+}$, respectively. The course of the reaction is determined by a suitable choice of reaction coordinate, which provides additional constraints. The reactions involve the terminated form of ATP, methyl triphosphate (MTP). This is a good approximation if we focus on the properties of the phosphate tail, and it makes the study more general, since all the nucleoside 5'triphosphates (such as GTP, CTP, and UTP) have the same tail.

\section{Method of Calculation}

A. Car-Parrinello Molecular Dynamics. We use the CarParrinello molecular dynamics (CPMD) method, ${ }^{35}$ which is based on density functional (DF) theory. The electron-ion interaction is described by ionic pseudopotentials based on the nonlocal, norm-conserving, and separable form suggested by Troullier and Martins. ${ }^{36}$ We use nonlinear core corrections for the $\mathrm{Mg}$ pseudopotential to include the contribution of inner electron shells in $\mathrm{Mg}^{2+}$, which interact with water and phosphate oxygens. Periodic boundary conditions are employed, and the plane wave basis has a kinetic energy cutoff of $80 \mathrm{Ry}$, using a single point $(\mathbf{k}=0)$ in the Brillouin zone. The generalized gradient-corrected approximation of Perdew, Burke, and Ernzerhof $(\mathrm{PBE})^{37}$ is adopted for the exchange-correlation energy density. A benchmark calculation of an isolated $\mathrm{H}_{3} \mathrm{PO}_{4}$ molecule shows that calculated $\mathrm{P}-\mathrm{O}$ distances (1.482 and $1.612 \AA$ ) differ by less than $0.01 \AA$ from the MP2 results of Grein, ${ }^{38}$ while the difference in dihedral angle is $1.6^{\circ}$. The $\mathrm{Mg}-\mathrm{O}$ separation in $\mathrm{Mg}^{2+}$ hexahydrate results $(2.115 \AA)$ is somewhat larger than the MP2 result $2.081 \AA .{ }^{39}$

The Car-Parrinello method has been used extensively to study the properties of water, ${ }^{40-45}$ ion and molecule solvation, ${ }^{46-49}$ and simple chemical reactions in water, ${ }^{50,51}$ where fictitious electron masses between 600 and $1100 \mathrm{~m}_{\mathrm{e}}$ allow time steps of $0.1-0.2 \mathrm{fs}$. The hydrogen atoms are often replaced by deuterium in order to allow larger time steps. Here we use an electron mass of $400 m_{\mathrm{e}}$, which requires a relatively small time step of $0.072 \mathrm{fs}$ ( $3 \mathrm{au}$ ), and no hydrogen/deuterium replacement. This keeps the electronic solution closer to the Born-Oppenheimer energy surface and does not affect the dynamics significantly.

B. Model System. The model system consists of one deprotonated methyl triphosphate (MTP) anion complexed with $\mathrm{Mg}^{2+}$ and surrounded by 54 water molecules in a cubic box of side $13.1 \AA$. The system has a net charge of -2 localized over the solute and $\mathrm{Mg}^{2+}$ which is counter-balanced by a homogeneous positive background charge placed outside the supercell. The minimum interatomic distance between the solutes during simulations is $6.5 \AA$, which enables at least two full hydration shells for each MTP replica. A larger distance between the solutes would require a large number of water molecules and plane waves, rendering reactive MD simulations impracticable at present.

The MTP solution is initialized by embedding the $\mathrm{Mg}(\mathrm{MTP})^{2-}$ complex in a cubic box of side $12.44 \AA$ filled with 64 randomly oriented water molecules, and displacing the 10 overlapping water molecules (within $70 \%$ of Lennard-Jones radius, AMBER force field). ${ }^{52}$ The system is equilibrated by performing classical molecular dynamics at $310 \mathrm{~K}$ and ambient pressure. Using the TIP3P force field ${ }^{53}$ for water molecules, the box length of the system oscillates around $13.1 \AA$, which we have chosen as our fixed box length in the CPMD simulations. A system of this size leads to large fluctuations in volume at constant pressure, resulting in a bias in hydrolysis simulations with a plane wave basis set, where the total energy is volume/grid dependent.

The CPMD simulations were started from the final configuration of the classical MD run, and the mismatch between the DFT and classical potentials requires equilibration of the system. We scale the ionic velocities to $310 \mathrm{~K}$ whenever the tolerance $(10 \mathrm{~K})$ on ionic temperature is exceeded. The system is first thermalized for $1 \mathrm{ps}$, after which $1.5 \mathrm{ps}$ of microcanonical constant energy MD is performed, although this did not allow complete relaxation of the hydrogen bond network of water. The MTP hydrolysis simulations consist of sequential reaction slices, where for each value of reaction coordinate we run 1 ps of molecular dynamics. Each slice contains 0.3 ps of velocity scaling, followed by 0.7 ps of constant energy MD. Typical RMS values for the potential energy and temperature fluctuations are $8 \mathrm{kcal} / \mathrm{mol}$ and $15 \mathrm{~K}$, respectively.

The reactions discussed are very fast $(9-13 \mathrm{ps})$. Analysis of the hydrogen bond network reveals that our time scale accounts for rotation and libration of individual water molecules, but not water diffusion. This is manifest as small artificial cavities in the water environment as the reactions proceed. It has been demonstrated using classical force fields that the diffusion of water is slowed considerably in the vicinity of biomolecules ${ }^{54,55}$ and metal cations, ${ }^{56}$ and this effect and the small size of the periodic system hamper water diffusion. Calculations of the three reactions described below support this, yielding diffusion constants less than half of the reported bulk water value $D=$ $2.30 \times 10^{-9} \mathrm{~m}^{2} / \mathrm{s}^{57-59}$

C. Reaction Coordinates. The time scales of computer simulations based on DF theory are usually far too short to describe chemical reactions involving barrier crossings. One way to overcome this problem is to introduce reaction coordinates that constrain the system and drive the reaction over the barrier. Information about the optimum reaction path can then be found by studying different paths and the related activation energies.

We model the two possible ATP hydrolysis mechanisms discussed above. For the dissociative reaction we use the distance between the $\beta$ - and $\gamma$-phosphorus atoms corresponding to the stretching of the $\mathrm{P}-\mathrm{O}_{\mathrm{s}}-\mathrm{P}$ anhydride bridge. This choice of reaction coordinate has more flexibility than the distance between anhydride $\mathrm{O}_{\mathrm{s}}$ and $\mathrm{P}_{\gamma}$, since it incorporates bending of the $\mathrm{P}-\mathrm{O}_{\mathrm{s}}-\mathrm{P}$ angle. It also imposes no restrictions on the solvent molecules. For the associative reaction, where the solvent plays an active role, we constrain the distance between the lytic water $\mathrm{O}_{\mathrm{w}}$ and $\mathrm{P}_{\gamma}$.

More flexibility is obtained by using a third reaction coordinate

$$
Q_{\mathrm{PW}}=R_{\mathrm{PP}}-R_{\mathrm{POw}}
$$


where $R_{\mathrm{AB}}=\left|\boldsymbol{r}_{\mathrm{A}}-\boldsymbol{r}_{\mathrm{B}}\right|$. This is a linear combination of the above reaction coordinates, and it constrains the difference between these two distances. It is particularly convenient for studying proton transfer in hydrogen bonding, ${ }^{50}$ and it allows changes in the angle spanned by the two distance vectors (in this case $\mathrm{P}-\mathrm{P}-\mathrm{O}_{\mathrm{w}}$ ).

In addition to dynamical information obtained by constraining reaction coordinates, one must know the related change in free energy (work), and we adopt a widely used technique where the mean averaged force $f_{\mathrm{s}}$ is integrated with respect to the reaction coordinate $\mathrm{Q}$,

$$
\Delta F(Q)=-\int_{Q_{0}}^{Q} \mathrm{~d} Q^{\prime} f_{\mathrm{s}}\left(Q^{\prime}\right)
$$

The force $f_{\mathrm{s}}(Q)$ is obtained via the forces of constraint. In the case of the distance between a pair of atoms, it reduces to

$$
f_{s}(Q)=\lambda
$$

where it is equal to the time-averaged force of constraint. ${ }^{50,60}$

We also monitor the mean potential energy in the system. Since the mean temperatures within the reaction slices vary within $20 \mathrm{~K}$ (we do not use thermostats), we impose a temperature normalization in the potential energy by applying the formula

$$
\Delta E=\frac{3 N-6}{2} k_{\mathrm{B}}\left(\langle T\rangle-T_{0}\right)
$$

which converts the temperature difference into vibrational energy according to classical statistical mechanics.

\section{Results}

A. Properties of Triphosphate Molecules and Solvated Mg(MTP $)^{2-}$ Complex. The protonated neutral forms of ATP and GTP in the gas phase are shown in Figure 1(a,b), which also shows the corresponding terminated phosphate tail (MTP) and its $\operatorname{Mg}(\mathrm{MTP})^{2-}$ complex together with four water molecules belonging to the first coordination shell of $\mathrm{Mg}^{2+}$. The absence of solvating water causes a formation of intramolecular hydrogen bonds in the phosphate tail leading to a cyclic configuration, where $\mathrm{P}_{\alpha}$ and $\mathrm{P}_{\gamma}$ units are coupled. ${ }^{61}$ There is an additional $\mathrm{H}$-bond for ATP and GTP between an $\mathrm{O}_{\alpha}$ and a hydroxyl group in the ribose entity. In the case of ATP, the total energy differs from that of the linear phosphate tail configuration (one $\mathrm{H}$-bond less) by $8.3 \mathrm{kcal} / \mathrm{mol}$. The ATP and GTP molecules in Figure 1 are shown in their anti conformation, which according to the NMR experiments, ${ }^{18}$ is the dominant conformation of deprotonated ATP in water. The syn conformation is probably more stable in the gas phase, since it allows hydrogen bonding between the $\mathrm{H}-2$ in the adenine ring and one $\mathrm{O}_{\alpha}$ atom.

Structural properties of the triphosphate tails of abovementioned molecules are given in Table 1 together with the results for $\mathrm{Mg}(\mathrm{MTP})^{2-}$ complex in aqueous solution (see below) and experimental results for $\mathrm{Na}_{2} \mathrm{ATP} \cdot 3 \mathrm{H}_{2} \mathrm{O}^{19,20}$ and $\mathrm{Mg}_{2} \mathrm{P}_{2} \mathrm{O}_{7}$ • $6 \mathrm{H}_{2} \mathrm{O}^{22}$ crystal salts. There are few differences between the ATP, GTP, and MTP forms, indicating that the triphosphate part is insensitive to the changes in other groups (ribose, adenine/ guanosine). A slight deviation of the $\mathrm{C}-\mathrm{O}_{\mathrm{s}}$ bond length and $\mathrm{C}-\mathrm{O}_{\mathrm{s}}-\mathrm{P}$ angle in MTP is related to the terminated methyl group and its rotation. The calculated electrostatic point charges (ESP) show no change in the individual atomic sites of these three molecules: the phosphorus atoms are strongly positive, and the oxygens have varying negative charges (see especially the anhydride oxygens, $\mathrm{O}_{\mathrm{s}}$ ). The MTP has a small dipole moment,

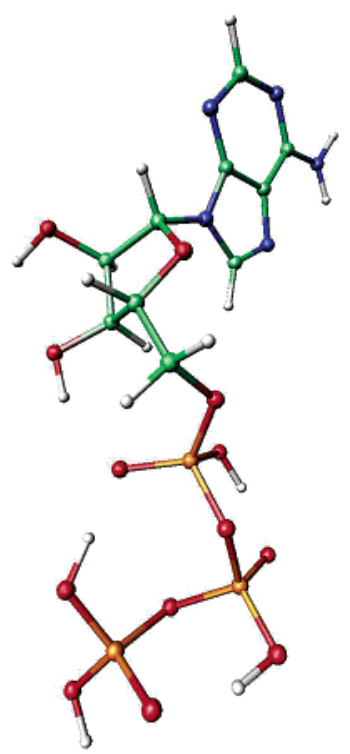

(a)

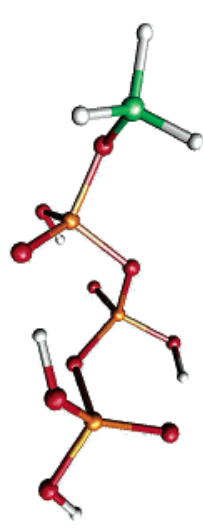

(c)

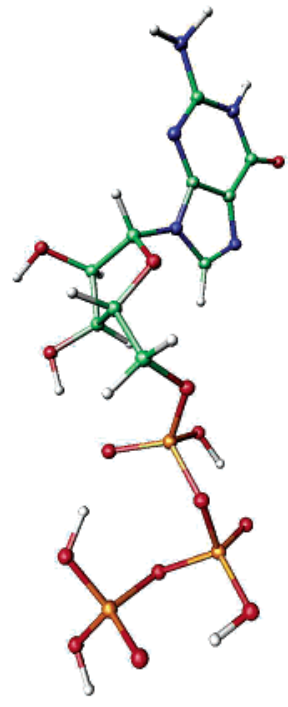

(b)

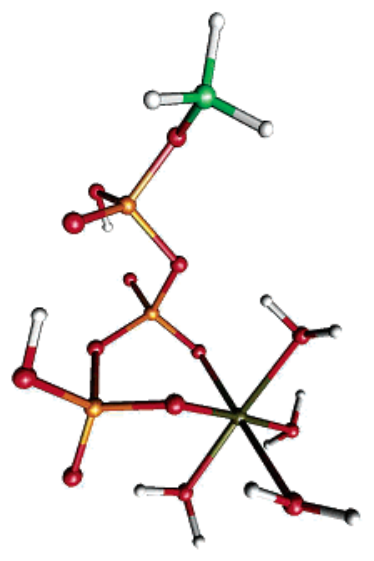

(d)
Figure 1. Structures of neutral (a) ATP, (b) GTP, (c) MTP, and (d) $\mathrm{Mg}(\mathrm{MTP}) \cdot 4 \mathrm{H}_{2} \mathrm{O}$. C atoms are green, $\mathrm{H}$ atoms white, $\mathrm{O}$ atoms red, $\mathrm{N}$ atoms blue, and $\mathrm{P}$ atoms orange.

but the ESP charges show that there is no negative net charge on the terminal phosphate.

Addition of the hydrated $\mathrm{Mg}^{2+}$ to MTP (and removal of two protons) leads to a stable bidentate chelate configuration between $P_{\beta}$ and $\mathrm{P}_{\gamma}$. As seen in Table 1 , the chelate ring induces a clear change in the molecular properties, particularly in the two terminal phosphates: The $\mathrm{P}-\mathrm{O}$ bond lengths involving $\mathrm{Mg}$ coordinated and anhydride $\mathrm{O}$ atoms increase (especially the terminal $\mathrm{P}-\mathrm{O}_{\mathrm{s}}$ bond), the $\mathrm{P}-\mathrm{O}_{\mathrm{s}}-\mathrm{P}$ bridge angle opens to $125.7^{\circ}$ (close to the experimental value of $\mathrm{Mg}$-pyrophosphate), ${ }^{22}$ and $\beta$ - and $\gamma$-phosphates acquire a staggered configuration: $\mathrm{Mg}^{2+}$ is octahedrally coordinated, and the corresponding chelate angle $\left(\mathrm{O}_{\beta}-\mathrm{Mg}-\mathrm{O}_{\gamma}\right)$ is close to the strain-free value of $90^{\circ}$. The structural changes correlate with the ESP charges, where a significant charge increase in the $P_{\beta}$ and $\mathrm{P}_{\gamma}$ oxygens can be observed, while the corresponding $\mathrm{P}$ atoms become more positive $(\Delta q=0.2 e)$. The $\mathrm{Mg}$ remains strongly cationic, causing a large dipole moment in the system.

Data for solvated $\mathrm{Mg}(\mathrm{MTP})^{2-}$ complex (with four protons removed) was collected over seven sequences corresponding to a total $5.8 \mathrm{ps}$ of constraint-free MD. The structural parameters 
TABLE 1: Calculated Properties of ATP, GTP, MTP, and Mg(MTP) Complex in the Gas Phase, Together with Aqueous $\operatorname{Mg}\left(\mathrm{MTP}^{2-}\right.$ and Experimental Crystal Structures of ATP/Pyrophosphate Salts ${ }^{a}$

\begin{tabular}{|c|c|c|c|c|c|c|}
\hline & ATP & GTP & MTP & $\mathrm{Mg}(\mathrm{MTP}) \cdot 4 \mathrm{H}_{2} \mathrm{O}$ & MTP(aq.) $)^{b}$ & Exp.(crystal) ${ }^{c}$ \\
\hline $\mathrm{P}=\mathrm{O}_{2}$ & 1.50 & 1.50 & 1.50 & $1.50-1.55$ & $1.51-1.55$ & $1.50 / 1.51$ \\
\hline $\mathrm{P}-\mathrm{O}_{1}$ & 1.57 & 1.57 & 1.57 & 1.58 & & "/" \\
\hline $\mathrm{P}-\mathrm{O}_{\mathrm{s}}$ & $1.58,1.65$ & $1.58,1.65$ & $1.59,1.65$ & $1.60-1.70$ & $1.62-1.70$ & $1.61 / 1.620$ \\
\hline $\mathrm{C}-\mathrm{O}_{\mathrm{s}}$ & 1.48 & 1.48 & 1.46 & 1.46 & 1.46 & $1.42 / \ldots$ \\
\hline $\mathrm{O}_{1}-\mathrm{H}$ & $0.98,1.04$ & $0.98,1.04$ & $0.98,1.04$ & 1.04 & & \\
\hline $\mathrm{H} \cdots \mathrm{O}_{2}$ & $1.55-1.67$ & $1.54-1.68$ & $1.50-1.69$ & $1.57,1.65$ & & \\
\hline $\mathrm{Mg}-\mathrm{O}$ & & & & $2.05-2.18$ & 2.15 & .../2.08 \\
\hline $\mathrm{P}-\mathrm{O}_{\mathrm{s}}-\mathrm{P}$ & 119.5 & 119.6 & 119.3 & $117.5,125.7$ & $128.2,128.3$ & 136.7/125.6 \\
\hline $\mathrm{P}-\mathrm{O}_{\mathrm{s}}-\mathrm{C}$ & 120.0 & 120.2 & 118.9 & 119.2 & 119.1 & $122.9 / \ldots$ \\
\hline $\mathrm{O}-\mathrm{Mg}-\mathrm{O}$ & & & & $75.6-99.6,173.8$ & $90.0,171.3$ & $\ldots / 89.5,174.1$ \\
\hline $\mathrm{Q}(\mathrm{P})$ & $0.84-0.93$ & $0.83-0.92$ & $0.88-0.95$ & $0.99,1.14$ & & \\
\hline $\mathrm{Q}\left(\mathrm{O}_{1}\right)$ & -0.45 & -0.45 & -0.45 & -0.53 & & \\
\hline $\mathrm{Q}\left(\mathrm{O}_{2}\right)$ & -0.52 & -0.52 & -0.51 & $-(0.54-0.83)$ & & \\
\hline $\mathrm{Q}\left(\mathrm{O}_{\mathrm{s}}\right)$ & $-(0.27-0.43)$ & $-(0.26-0.42)$ & $-(0.26-0.42)$ & $-(0.29-0.57)$ & & \\
\hline $\mathrm{Q}(\mathrm{Mg})$ & & & & 1.44 & & \\
\hline dipole & 5.4 & 7.2 & 2.2 & 13.2 & & \\
\hline
\end{tabular}

${ }^{a}$ Bond lengths in $\AA$, bond angles in degrees, atomic charges (e) and dipole moments (Debye). $\mathrm{O}_{1}$ and $\mathrm{O}_{2}$ label the protonated and unprotonated nonbridging oxygens, respectively. ${ }^{b}$ Average values. ${ }^{c}$ Experimental crystal salts $\mathrm{Na}_{2} \mathrm{ATP} \cdot 3 \mathrm{H}_{2} \mathrm{O}$ [Ref. [19,20]] and $\mathrm{Mg}_{2} \mathrm{P}_{2} \mathrm{O}_{7} \cdot 6 \mathrm{H}_{2} \mathrm{O}$ [Ref. [22]].

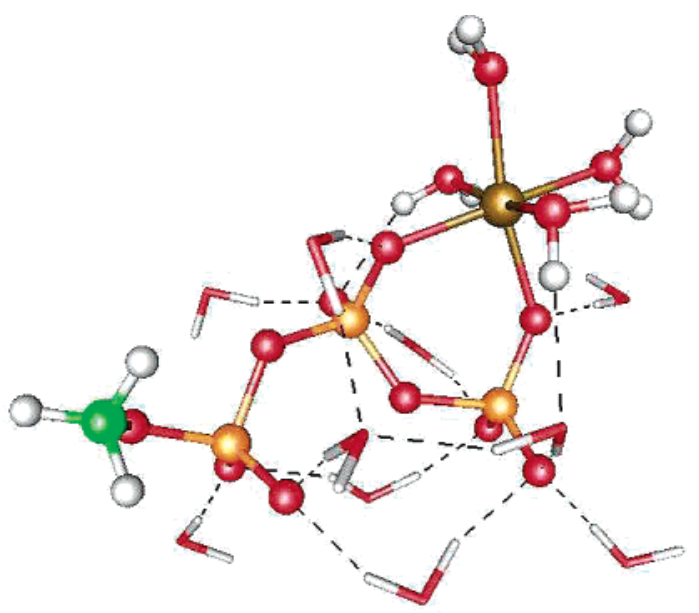

(a)

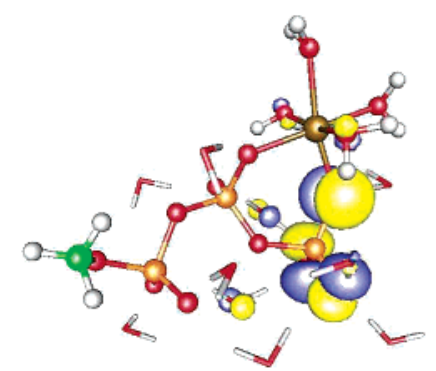

(b)

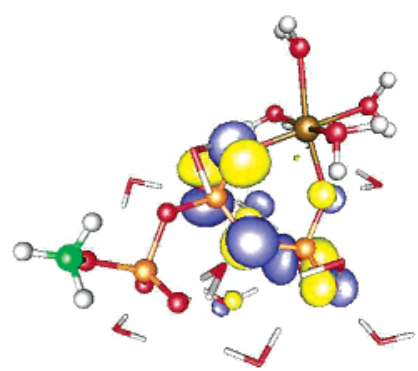

(c)
Figure 2. Snapshot of the solvated $\operatorname{Mg}(\mathrm{MTP})^{2-}$ complex: (a) the first solvation shell, $(b-c)$ the two highest occupied Kohn Sham orbitals (HOMO and HOMO-1) corresponding to the eigenvalues -2.63 and $-2.86 \mathrm{eV}$, respectively. The dashed lines indicate hydrogen bonds, and the $\mathrm{Mg}$ atom is brown. See caption of Figure 1.

(average values) are listed in Table 1, and a snapshot of the solute and nearby water molecules is shown in Figure 2. In contrast to the previous cases, the triphosphate is now completely deprotonated (charge), and no intramolecular H-bonds can be observed. The solute interacts strongly with the water environment, and a detailed analysis of the H-bond network reveals (see Figure $2 \mathrm{a}$ ) that the nonbridging $P_{\beta}$ and $\mathrm{P}_{\gamma}$ oxygens have 2.5 hydrogen bonds each on average, while the same number is 2.0 for $\mathrm{P}_{\alpha}$ and 1.0 for $\mathrm{Mg}$-coordinating oxygens. The anhydride oxygens do not participate in hydrogen bonding, ${ }^{62}$ suggesting that the tail of triphosphate is strongly hydrophilic, enhancing its susceptibility for hydrolysis.

The structural parameters of $\mathrm{Mg}(\mathrm{MTP})^{2-}$ complex (Table 1) illustrate the effect of water solvation. The bond lengths and bond angles are similar to those in the unsolvated $\mathrm{Mg}$-chelate, the most obvious difference being in the $\mathrm{P}_{\alpha}-\mathrm{O}_{\mathrm{s}}-\mathrm{P}_{\beta}$ angle, which is $128.2^{\circ}$ in the case of the solvated complex, the same as $\mathrm{P}_{\beta}-\mathrm{O}_{\mathrm{s}}-\mathrm{P}_{\gamma}$. The corresponding dihedral alignments of phosphates (defined via $\mathrm{O}-\mathrm{P}-\mathrm{P}-\mathrm{O}$ ) have asymmetric distributions between 20 and $80^{\circ}$ with skewed maxima around $35^{\circ}$ (staggered value $60^{\circ}$ ). The coordination of $\mathrm{Mg}^{2+}$ remains octahedral (see $\mathrm{O}-\mathrm{Mg}-\mathrm{O}$ angles) with an average $\mathrm{Mg}-\mathrm{O}$ bond length of $2.15 \AA$.

Analysis of the five anhydride $\mathrm{P}-\mathrm{O}_{\mathrm{s}}$ bonds shows that two bonds are weaker (longer) than the others: the terminal $\mathrm{P}_{\gamma}-\mathrm{O}_{\mathrm{s}}$ bond $(1.70 \AA)$ and the $\mathrm{P}_{\alpha}-\mathrm{O}_{\mathrm{s}}$ bond of the $\mathrm{P}_{\alpha}-\mathrm{O}_{\mathrm{s}}-\mathrm{P}_{\beta}$ bridge $(1.68 \AA)$. This suggests that there are two possible weak links in the system, in agreement with the observation that ATP undergoes hydrolysis directly to AMP under certain conditions. ${ }^{1}$

The two highest occupied molecular orbitals (HOMO) of the $\operatorname{Mg}(\mathrm{MTP})^{2-}$ solution are shown in Figure 2(b,c). These orbitals correspond to the extra charge of the system and are localized on the solute. The HOMO state is localized on the terminal phosphate with a small component on some nearby water molecules. The next lower state (HOMO-1) is spread over the $\mathrm{P}_{\beta}-\mathrm{O}_{\mathrm{s}}-\mathrm{P}_{\gamma}$ bridge and has some weight on nearby water molecules. Analysis of the lowest unoccupied molecular orbital (LUMO, not shown) reveals that the system has a large HOMO-LUMO gap (4.13 eV), and that the LUMO is completely delocalized over the water solvent.

B. MTP Hydrolysis Reactions. The MTP hydrolysis reaction in water is modeled using three reaction paths. The first two correspond to idealized cases of dissociative and associative reactions, where a single distance-dependent reaction coordinate is employed. Based on this experience, we have used a third, more complicated reaction coordinate that changes during the course of the reaction.

1. Dissociative Reaction. Here we constrain the distance between $\mathrm{P}_{\beta}$ and $\mathrm{P}_{\gamma}$ atoms, corresponding to separating the terminal phosphate from the rest of the solute. The energetics are shown in Figure 3, together with the forces of constraint and the total number of hydrogen bonds in the system. ${ }^{62}$ The work done (free energy change) in the system increases monotonically to $\Delta F=36.6 \mathrm{kcal} / \mathrm{mol}$, where the $\mathrm{P}-\mathrm{O}_{\mathrm{s}}$ bond 


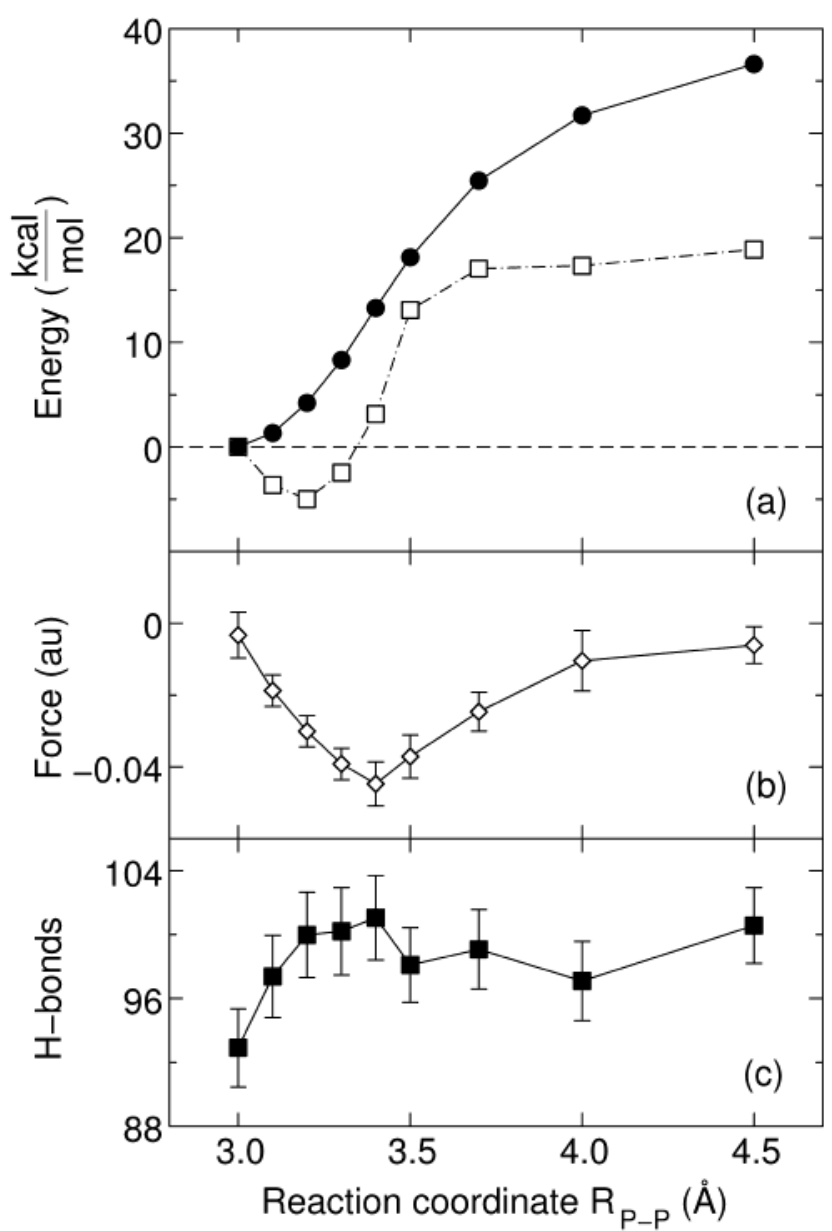

Figure 3. Reaction energetics of the dissociative reaction: (a) energies (full circles $\Delta F$, open squares $\Delta E_{\mathrm{p}}$ ), (b) forces (diamonds), and (c) total number of hydrogen bonds (full squares) during the simulation. Error bars show the RMS deviation.

is broken and a metastable $\mathrm{PO}_{3}{ }^{-}$unit is separated from the solute. At this point, the restoring force acting on the metaphosphate is very small. ${ }^{63}$ There is a marked difference between the free energy and the potential energy $\left(\Delta E_{\mathrm{p}}\right)$ at the beginning of the reaction, when $\Delta E_{\mathrm{p}}$ decreases to a minimum of -5.0 $\mathrm{kcal} / \mathrm{mol}$ at $3.2 \AA$. This drop in potential energy correlates with an increasing number of hydrogen bonds in the supercell, indicating a lack of equilibration when the reaction was started. We then estimate that the separation of $\mathrm{PO}_{3}{ }^{-}$raises the potential energy by $26-28 \mathrm{kcal} / \mathrm{mol}$ (at $3.7 \AA$ ), in reasonable agreement with $\Delta F \cdot{ }^{64}$ However, during the last three steps in the reaction, $\Delta E_{\mathrm{p}}$ is almost constant, whereas $\Delta F$ increases over $10 \mathrm{kcal} /$ mol. Apparently, the solvent imposes a friction-like force on $\mathrm{PO}_{3}{ }^{-}$during this stretching stage.

The evolution of the $\mathrm{P}-\mathrm{O}_{\mathrm{s}}-\mathrm{P}$ bridge, the distance between $\mathrm{P}_{\gamma}$ and the nearest (lytic) water oxygen $\left(\mathrm{O}_{\mathrm{w}}\right)$, and the internal $\mathrm{O}-\mathrm{P}-\mathrm{O}$ angle in the terminal phosphate are shown in Figure 4. A gradual change with the free energy $\Delta F$ is seen in the $\mathrm{P}-\mathrm{O}_{\mathrm{s}}$ bond distance, where the breaking of the covalent bond can be assigned to $3.4-3.5 \AA$ (see also $\Delta E_{\mathrm{p}}$ ). The variation in the $\mathrm{P}-\mathrm{O}_{\mathrm{s}}-\mathrm{P}$ angle supports this conclusion: its value increases from $128^{\circ}$ to $143^{\circ}$ at $3.5 \AA$, after which the angular fluctuations (not shown) increase dramatically. The resulting metaphosphate acquires a planar geometry as the $\mathrm{O}-\mathrm{P}-\mathrm{O}$ angle converges to $120^{\circ}$.

The water environment plays a passive role throughout the reaction, as seen in Figure $4 \mathrm{a}$, where the $\mathrm{P}-\mathrm{O}_{\mathrm{w}}$ distance for the nearest water molecule remains above $3.6 \AA$. The effect of

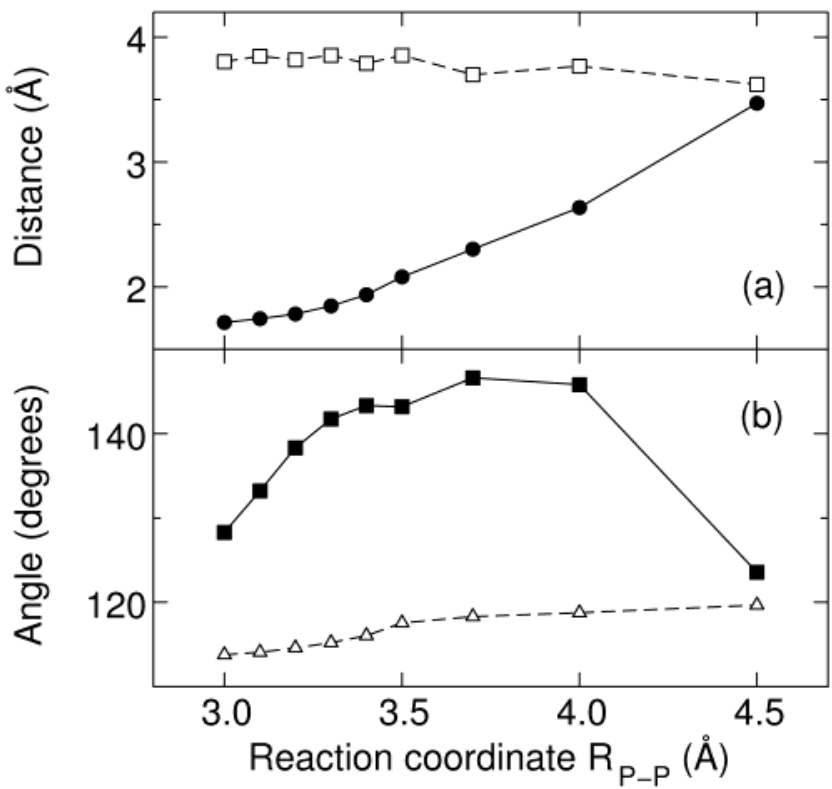

Figure 4. Evolution of the structural parameters during the dissociative reaction: (a) bonds (open squares $\mathrm{P}_{\gamma}-\mathrm{O}_{\mathrm{w}}$, full circles $\mathrm{P}_{\gamma}-\mathrm{O}_{\mathrm{s}}$ ) and (b) angles (full squares $\mathrm{P}_{\beta}-\mathrm{O}-\mathrm{P}_{\gamma}$, triangles $\mathrm{O}-\mathrm{P}_{\gamma}-\mathrm{O}$ for terminal phosphate).

the solute on the water dynamics was tested by calculating a $\mathrm{PO}_{3}{ }^{-}$ion embedded in $54 \mathrm{H}_{2} \mathrm{O}$ molecules in a cubic cell of side $12.1 \AA$. The metaphosphate reacts spontaneously (i.e., without barrier) with a water molecule, leading to a $\mathrm{HPO}_{4}{ }^{2-}$ anion and a proton, which diffuses according to the Grotthuss mechanism..$^{42,65}$ It is probable that the $\mathrm{PO}_{3}{ }^{-}$would react with water if sufficiently long MD runs could be performed on a larger sample.

2. Associative Reaction. The reaction coordinate chosen here was the distance between $\mathrm{P}_{\gamma}$ and $\mathrm{O}_{w}$, where $\mathrm{O}_{\mathrm{w}}$ belongs to the nearest $\mathrm{H}_{2} \mathrm{O}$ in the previous constraint-free $\mathrm{MD}$ run. The choice of lytic water places it on the opposite side of the terminal phosphate with respect to the $\mathrm{P}-\mathrm{O}_{\mathrm{s}}$ anhydride bond. The reaction energetics, the force of constraint, and the total number of hydrogen bonds in the system are shown in Figure 5, and the corresponding structural parameters in Figure 6. As the reaction coordinate is reduced, the free energy rises gradually to its maximum value $\Delta F=39.1 \mathrm{kcal} / \mathrm{mol}$ at $1.9 \AA$, corresponding to a pentacovalent intermediate of $P_{\gamma}$ (see Figure 7) common in biochemistry. ${ }^{51,66}$ Further changes in the reaction coordinate cause the anhydride bond to dissociate as a $\mathrm{P}-\mathrm{O}_{\mathrm{w}}$ bond is formed and are seen as a decrease in both $\Delta F$ and $\Delta E_{\mathrm{p}}$.

The lack of equilibration (a drop in $\Delta E_{\mathrm{p}}$ at $2.9 \AA$, see also the number of $\mathrm{H}$-bonds) also affects the potential energy. A change of $10 \mathrm{kcal} / \mathrm{mol}$ in the energy maximum would bring $\Delta E_{\mathrm{p}}$ values close to the corresponding free energy change. ${ }^{64} \mathrm{~A}$ significant difference exists after the maximum, however, when $\Delta F$ changes only slightly in comparison with a steep drop of $15 \mathrm{kcal} / \mathrm{mol}$ in $\Delta E_{\mathrm{p}}$. This is a consequence of our choice of reaction coordinate, where we do not control the negative work coming from the dissociation of the $\mathrm{P}-\mathrm{O}_{\mathrm{s}}$ bond. The final energy increase between the reactants and end products is related to the very short dynamics after the reaction maximum. The large cavity in the water structure next to the terminal phosphate group has had insufficient time to relax through water diffusion. This explains the substantial potential energy increase observed.

The reaction can be summarized as follows: First, a hydrogen bond between the lytic water and an unsaturated $\mathrm{O}_{\gamma}$ is gradually compressed (see the H-bond distance and angle in Figure 6) 


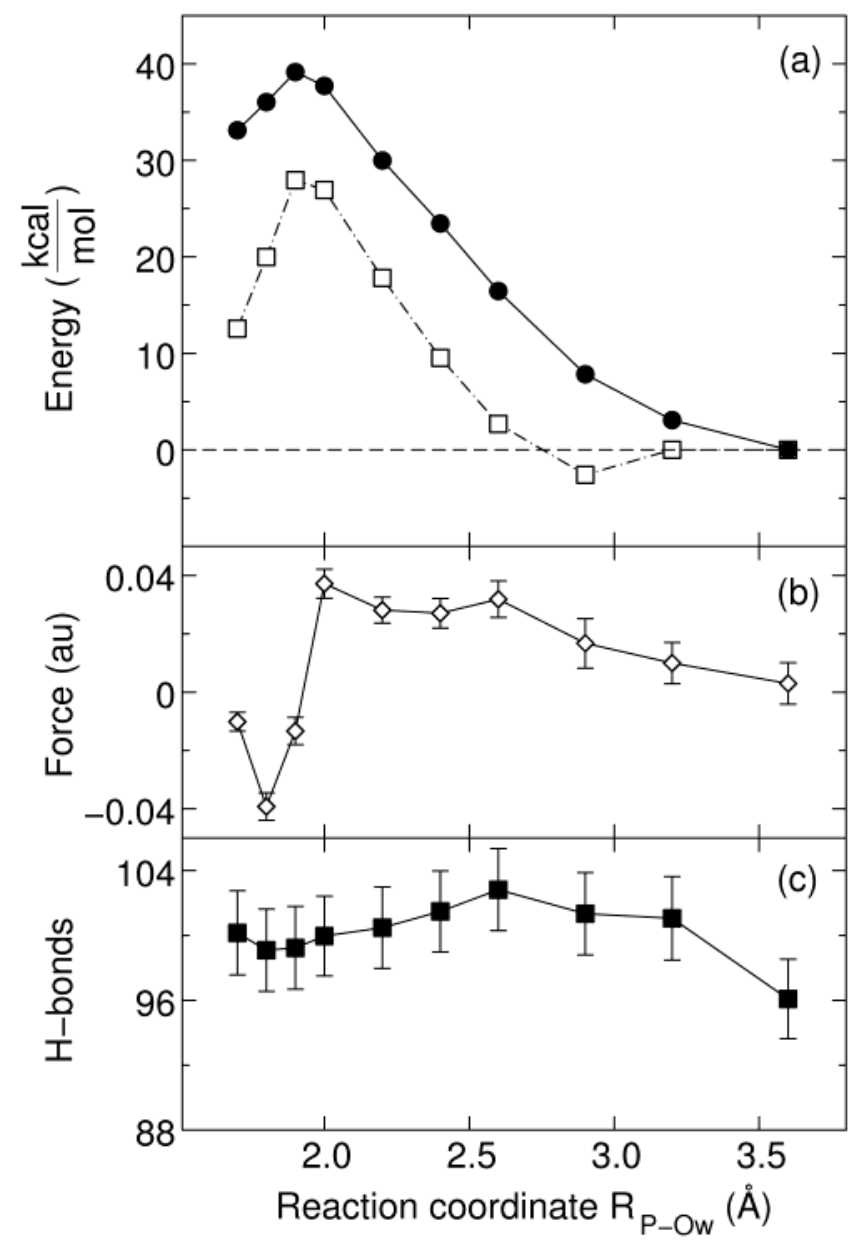

Figure 5. Reaction energetics of the associative reaction: (a) energies, (b) forces, and (c) total number of hydrogen bonds during the simulation. See caption of Figure 3.

until $\mathrm{H}_{2} \mathrm{O}$ rotates in a symmetric orientation at $2.2 \AA$, where both water protons form equivalent (weak) hydrogen bonds with the phosphate oxygens. A further reduction of the reaction coordinate triggers a proton transfer from $\mathrm{O}_{\mathrm{w}}$ to $O_{\gamma}$ at $1.9 \AA$ with a change in $\mathrm{P}-\mathrm{O}_{\mathrm{w}}$ bonding (see Figure $5 \mathrm{~b}$ ) leading to the pentacoordinated structure in Figure 7. Reducing the reaction coordinate to an intramolecular value of $1.7 \AA$ results in a $\mathrm{H}_{2} \mathrm{PO}_{4}^{-}$anion that has kept its ligand to $\mathrm{Mg}^{2+}$ together with the solute. At this point, removing the constraint affects the system only slightly: the average potential energy decreases by $1.9 \mathrm{kcal} / \mathrm{mol}$, and the $\mathrm{P}-\mathrm{O}$ bond oscillates around $1.67 \AA$.

This result shows clear similarities to the study by Okimoto et al. ${ }^{33}$ of ATP hydrolysis in myosin. The environment in the latter differed (isolated active site of myosin), but the same Walden inversion mechanism is apparent, where the improper dihedral angle - defined through the nonbridging oxygens and $\mathrm{P}_{\gamma}-$ changes its sign after the reaction intermediate in Figure 7 is passed. The estimate $\Delta F=42.0 \mathrm{kcal} / \mathrm{mol}$ is similar to ours, the main difference being in the location of transition state, which is $2.17 \AA$ in ref $33(T=0)$ compared with our estimate 1.9-2.0 $\AA(T=310 \mathrm{~K})$. The transition state location is determined by proton transfer, which is related to the $\mathrm{p} K_{\mathrm{a}}$ of the specific environment in question. Furthermore, the direction of the reaction can affect the transition state, since the number of protons in phosphates can change easily under neutral conditions (buffering).

3. Flexible Reaction. The above paths describe possible hydrolysis reactions, but both have significant drawbacks: the

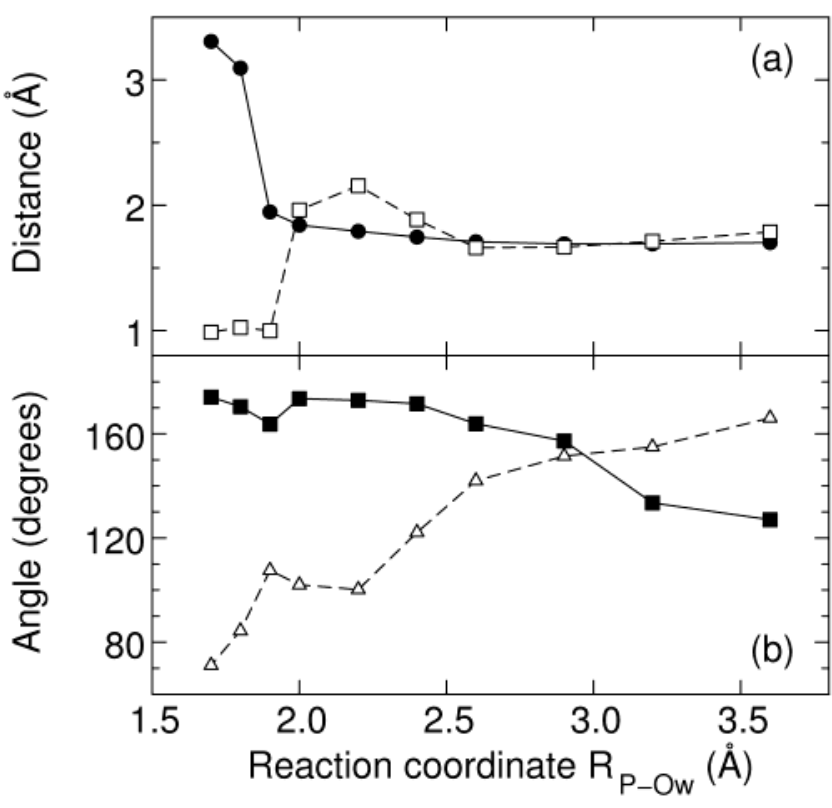

Figure 6. Evolution of the structural parameters during associative reaction: (a) bonds (open squares $\mathrm{O}-\mathrm{H}_{\mathrm{w}}(\mathrm{O}$ : terminal phosphate), full circles $\mathrm{P}_{\gamma}-\mathrm{O}_{\mathrm{s}}$ ) and (b) angles (full squares $\mathrm{O}-\mathrm{P}_{\gamma}-\mathrm{O}_{\mathrm{w}}(\mathrm{O}$ : terminal phosphate), triangles $\mathrm{O}-\mathrm{H}_{\mathrm{w}}-\mathrm{O}_{\mathrm{w}}$ ).

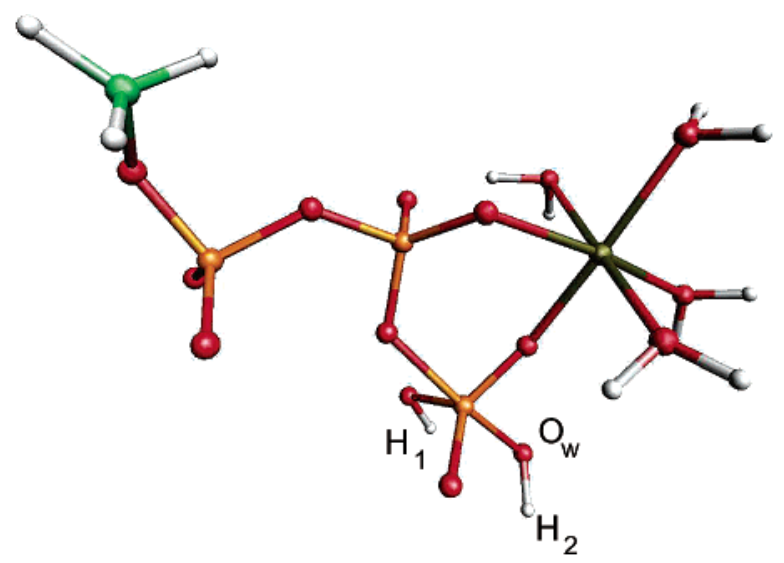

Figure 7. Pentacoordinated transition state geometry. $\mathrm{C}$ atoms green, $\mathrm{H}$ atoms white, $\mathrm{O}$ atoms red, $\mathrm{P}$ atoms orange, $\mathrm{Mg}$ atom brown.

dissociative reaction leads to a metaphosphate, and bond breaking and formation in the associative reaction happen so rapidly that the solvent cannot relax completely. Further insight can be obtained by studying a more flexible reaction with the reaction coordinate $Q_{\mathrm{PW}}$ [eq 2]. The energetics, forces of constraint, and bond distances are shown in Figure 8. During the course of the reaction (see also Figure 9) $Q_{\mathrm{PW}}$ works well, up to a point where it must be changed to the two distance coordinates used above (see forces in Figure 8b).

In contrast to the previous reactions, the water environment is properly thermalized. This is shown by the good correspondence between $\Delta E_{\mathrm{p}}$ and $\Delta F$ during the reaction, the only difference being in the reaction tail after the maximum. The snapshots of the solute and lytic water in Figure 9 show that the reaction involves two intermediates. At the beginning (Figure 9a), increasing $Q_{\mathrm{PW}}$ causes a stretching in the $\mathrm{P}-\mathrm{O}_{\mathrm{s}}$ bond and a reduction in the $\mathrm{P}-\mathrm{O}_{\mathrm{w}}$ distance. This procedure works well to the point $Q_{\mathrm{PW}}=0.6 \AA(23.7 \mathrm{kcal} / \mathrm{mol})$, where a cleavage of a planar $\mathrm{PO}_{3}{ }^{-}$occurs. At $0.9 \AA$ (Figure 9b, intermediate 1), the $\mathrm{P}-\mathrm{O}_{\mathrm{w}}$ distance increases slightly due to the weakened restoring force between the solute and $\mathrm{PO}_{3}{ }^{-}$, and new reaction coordinates are needed to bring the lytic water and metaphosphate together. 


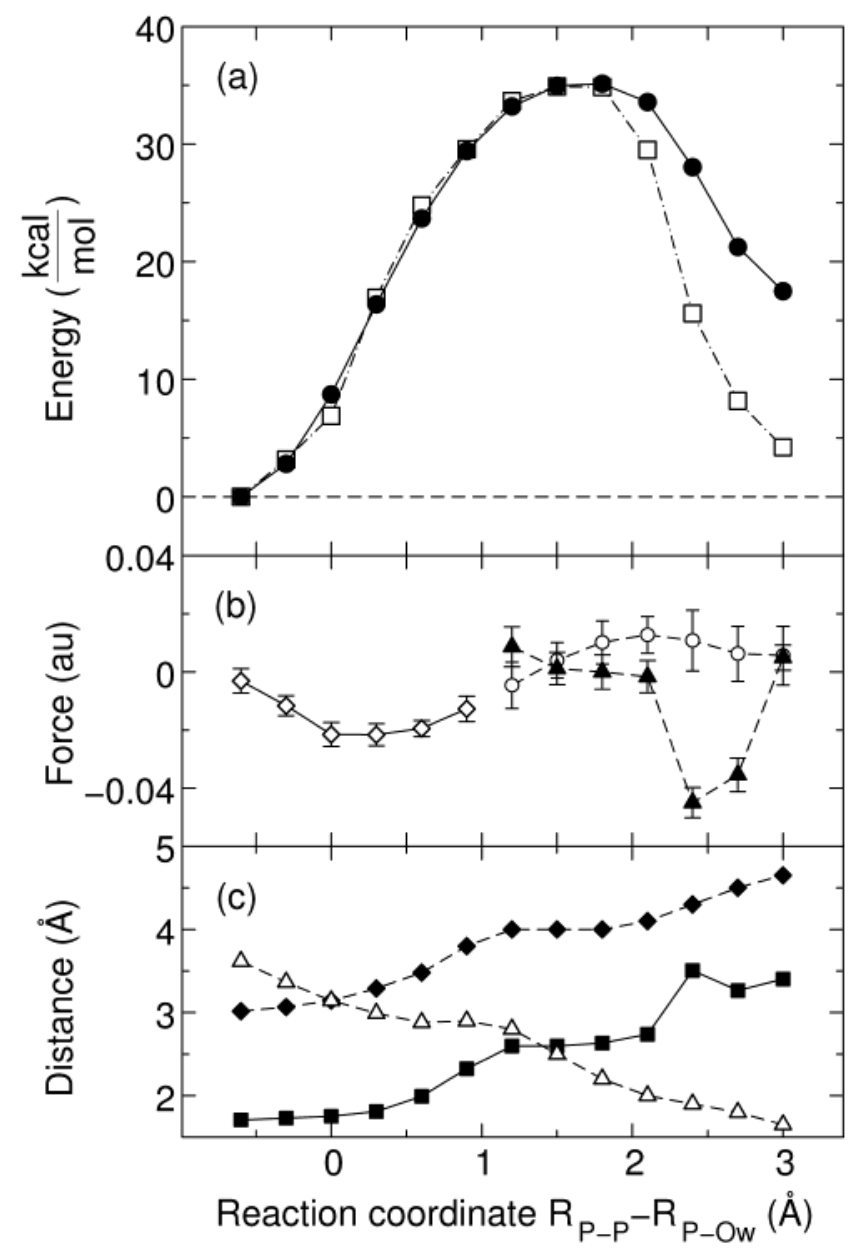

Figure 8. Reaction energetics of the flexible reaction: (a) energies (full circles $\Delta F$, open squares $\Delta E_{\mathrm{p}}$, (b) forces (open diamonds $Q_{\mathrm{PW}}$, open circles $\mathrm{P}_{\beta}-\mathrm{P}_{\gamma}$, closed triangles $\mathrm{P}_{\gamma}-\mathrm{O}_{\mathrm{w}}$ ), and (c) bond distances (full squares $\mathrm{P}_{\gamma}-\mathrm{O}_{\mathrm{s}}$, open triangles $\mathrm{P}_{\gamma}-\mathrm{O}_{\mathrm{w}}$, full diamonds $\mathrm{P}_{\beta}-\mathrm{P}_{\gamma}$ ) during the simulation.

After a gradual shortening of $\mathrm{P}-\mathrm{O}_{\mathrm{w}}$ (and separation of $\mathrm{P}-\mathrm{O}_{\mathrm{s}}$ ), the hydrogen bond between $\mathrm{PO}_{3}{ }^{-}$and $\mathrm{H}_{2} \mathrm{O}$ breaks at $Q_{\mathrm{PW}}=$ $1.5 \AA$ (the $\mathrm{P}-\mathrm{O}_{\mathrm{w}}$ distance $2.5 \AA$ ), the water rotates to form $\mathrm{H}$-bonds with the environment, and one $\mathrm{O}_{\mathrm{w}}$ lone pair interacts tetrahedrally with $\mathrm{P}_{\gamma}$. This configuration corresponds to our flat reaction maximum of $35.1 \mathrm{kcal} / \mathrm{mol}$ at $1.5-1.8 \AA$ (Figure 9c, intermediate 2), where the forces of constraint change their sign: $\mathrm{P}-\mathrm{O}_{\mathrm{s}}$ becomes repulsive and $\mathrm{P}-\mathrm{O}_{\mathrm{w}}$ attractive. As the overlap between $\mathrm{P}_{\gamma}$ and $\mathrm{O}_{\mathrm{w}}$ increases, the water $\mathrm{O}-\mathrm{H}$ bonds weaken, and (at $Q_{\mathrm{PW}}=2.4 \AA, R_{\mathrm{POw}}=1.9 \AA$ ) one of the protons finally jumps to a nearby $\mathrm{H}_{2} \mathrm{O}$, launching a proton diffusion in the solvent according to the Grotthuss mechanism. In our calculation, the diffusing proton returns after a small loop to one of the unsaturated oxygens of the newly formed phosphate, leading to the end product $\mathrm{H}_{2} \mathrm{PO}_{4}^{-}$(Figure 9d).

The reaction barrier height obtained $(35.1 \mathrm{kcal} / \mathrm{mol})$ is somewhat lower than in the associative reaction, and the reaction path differs considerably; it is energetically favorable to break first the $\mathrm{P}-\mathrm{O}_{\mathrm{s}}$ bond, followed by the nucleophilic attack of water. The $\mathrm{Mg}$ coordination also shows a marked difference with respect to the second reaction. The terminal phosphate loses contact with $\mathrm{Mg}^{2+}$ already at $Q_{\mathrm{PW}}=0.3 \AA$, where the dihedral configuration of $\beta$ - and $\gamma$-phosphates changes from skewed to staggered. This is supported by the Coulomb repulsion and solvation of the terminal phosphate, and the undercoordination of $\mathrm{Mg}^{2+}$ (five ligands) remains throughout the remainder of the simulation.

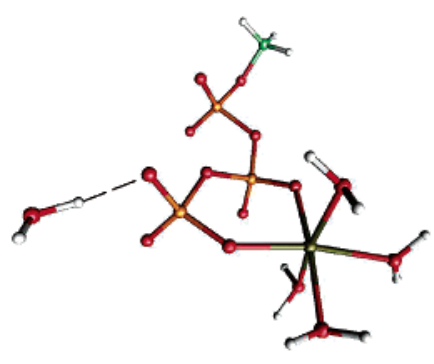

(a)

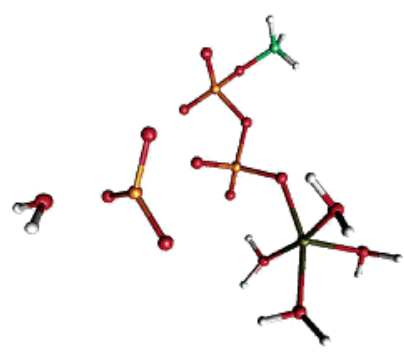

(c)

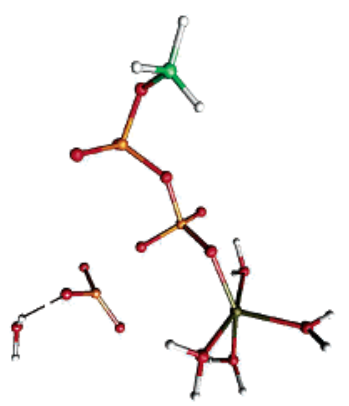

(b)

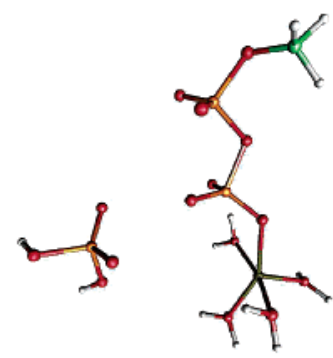

(d)
Figure 9. Path of the flexible reaction. See caption of Figure 7. The dashed lines show selected hydrogen bonds.

The energy changes of the system after hydrolysis are $\Delta E_{\mathrm{p}}$ $=4.2 \mathrm{kcal} / \mathrm{mol}$ and $\Delta F=17.5 \mathrm{kcal} / \mathrm{mol}$. The difference between these two values can be attributed to the uncontrolled jump of one proton after the reaction maximum is reached. Other studies have shown this type of proton transfer can be controlled by constraining the proton coordination number of $\mathrm{O}_{\mathrm{w}}{ }^{45,51}$ The contribution of entropy to $\Delta F$ is small, at least in $\mathrm{P}-\mathrm{O}_{\mathrm{s}}$ bond breaking (see reaction maxima in Figure $8 \mathrm{a}$ ). The experimental results of George et al. ${ }^{9}$ indicate that the entropy contribution in pyrophosphate hydrolysis is $-1.4 \mathrm{kcal} / \mathrm{mol}$ at $298 \mathrm{~K}$. The solvent structure in our final configuration is not fully relaxed, since the displacement of the metaphosphate has created a small cavity. This leads to the undercoordination of $\mathrm{Mg}$, and the initial anhydride $\mathrm{O}_{\mathrm{s}}$, which is now unsaturated, has fewer H-bonds with the solvent. The hydrogen bond strength in bulk ice is 6.7 $\mathrm{kcal} / \mathrm{mol},{ }^{67}$ so that these effects may account for a change of order $-10 \mathrm{kcal} / \mathrm{mol}$ in free energy. Our result for $\Delta E_{\mathrm{p}}$ suggests that the hydrolysis reaction is exothermic when a complete solvation of the model system is assumed, in agreement with the conclusions of Saint-Martin et al. for a solvated pyrophosphate. ${ }^{68}$

C. Role of Magnesium. The presence of $\mathrm{Mg}^{2+}$ is known to enhance the ATP hydrolysis rate. ${ }^{10,11}$ As described in section 3.1, binding of $\mathrm{Mg}$ results in a formation of a stable $\mathrm{Mg}(\mathrm{MTP})$ chelate together with a significant elongation of the terminal $\mathrm{P}-\mathrm{O}_{\mathrm{s}}$ bond. This property has already been demonstrated by the gas-phase calculations of Mg-pyrophosphate complexes. ${ }^{28,30}$ However, the present calculations show that the energy needed to break this bond in an aqueous environment is still over 20 $\mathrm{kcal} / \mathrm{mol}$, and other reaction coordinates must be considered. Although it has been proposed that $\mathrm{Mg}^{2+}$ introduces strain into the terminal $\mathrm{P}-\mathrm{O}_{\mathrm{s}}-\mathrm{P}$ bridge, ${ }^{22,30}$ we think that the $\mathrm{Mg}$ cation fits smoothly into the pocket created by the two terminal phosphates. Little change is observed in the angular (see Table 1) and torsional properties with respect to the other (free) $\mathrm{P}-\mathrm{O}_{\mathrm{s}}-\mathrm{P}$ bridge in the solute, and the weakened $\mathrm{P}-\mathrm{O}_{\mathrm{s}}$ bond is 
TABLE 2: Response of the Solvated $\mathrm{Mg}\left(\mathrm{MTP}^{2-}{ }^{2}\right.$ Complex to the Constrained Mg-Displacement ${ }^{a}$

\begin{tabular}{|c|c|c|c|c|c|c|c|}
\hline Constraint & $\mathrm{P}-\mathrm{O}_{\mathrm{s}}$ & $\mathrm{P}-\mathrm{O}_{\mathrm{s}}-\mathrm{P}$ & $\mathrm{Mg}-\mathrm{O}_{\beta, \gamma}$ & $\mathrm{Mg}-\mathrm{O}_{\mathrm{s}}$ & $\mathrm{O}_{\beta}-\mathrm{Mg}-\mathrm{O}_{\gamma}$ & $\Delta F$ & Force \\
\hline Free MD & $1.62 / 1.70$ & 128.3 & $2.15 / 2.17$ & 3.63 & 88.6 & & \\
\hline $\mathrm{Mg}-\mathrm{O}_{\beta}$ & $1.61 / 1.71$ & 126.9 & $1.90 / 2.20$ & 3.55 & 91.0 & 5.2 & 41.8 \\
\hline $\mathrm{Mg}-\mathrm{O}_{\mathrm{s}}$ & $1.61 / 1.69$ & 134.8 & $2.15 / 2.10$ & 3.20 & 103.3 & 4.1 & 19.1 \\
\hline $\mathrm{Mg}-\mathrm{O}_{\mathrm{s}}$ & $1.63 / 1.69$ & 135.0 & $2.14 / 2.14$ & 2.80 & 112.6 & 12.0 & 20.3 \\
\hline
\end{tabular}

${ }^{a}$ Constrained distances are indicated by boldfaced values. Distances in $\AA$, bond angles in degrees, free energy changes $(\Delta F)$ and forces $\left(f_{\mathrm{s}}\right)$ in $\mathrm{kcal} / \mathrm{mol}$.

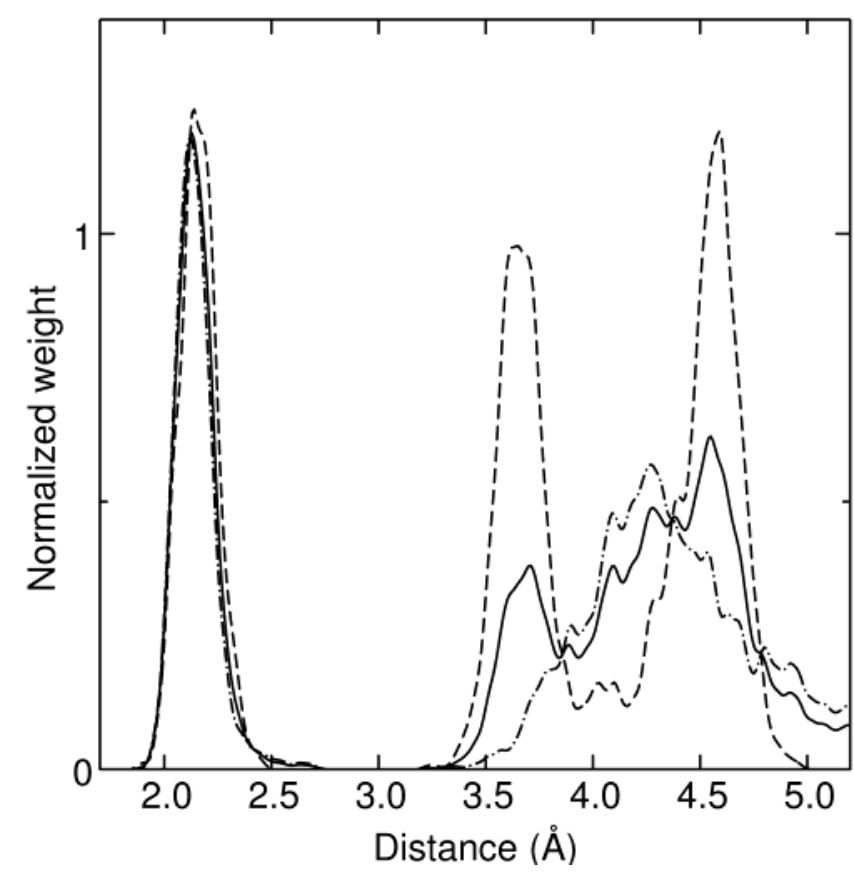

Figure 10. Radial distribution function of $\mathrm{Mg}-\mathrm{O}$ distances. Solid line: all $\mathrm{Mg}-\mathrm{O}$ distances; dashed line: $\mathrm{O}$ belongs to MTP, dashdotted line: $\mathrm{O}_{\mathrm{w}}$ belongs to water.

simply one component of the newly formed bidentate chelate. Furthermore, the $\mathrm{Mg}-\mathrm{O}$ radial distributions shown in Figure 10 and the corresponding $\mathrm{O}-\mathrm{Mg}-\mathrm{O}$ angles (Table 1) indicate that the water and MTP oxygens form equally tight ionic bonds with $\mathrm{Mg}^{2+}$. The octahedral solvation shell of $\mathrm{Mg}$ is preserved, in agreement with the calorimetric measurements of $\mathrm{Mg}(\mathrm{ATP})$ complexes, where the Mg-chelate formation is seen as an entropy-driven process with a very small change in enthalpy. ${ }^{17}$

The above reactions have ignored the possible active role of the $\mathrm{Mg}^{2+}$ ion in hydrolysis, and we have made further simulations where the system response to constrained $\mathrm{Mg}-\mathrm{O}$ distances is monitored. The results for three $\mathrm{Mg}$ displacements are given in Table 2 together with the corresponding constraintfree values. First, $\mathrm{Mg}^{2+}$ is moved toward the nearest $\beta$-phosphate oxygen so that the $\mathrm{Mg}-\mathrm{O}$ distance is $1.90 \AA$ (a step of 0.25 $\AA$ ). The bidentate chelate properties show almost no change, the energy increases slightly, and the force of constraint becomes large. Assuming that the anhydride oxygen $\left(\mathrm{O}_{\mathrm{s}}\right)$ is the weakest link in the system, we have repeated the same procedure for the $\mathrm{Mg}-\mathrm{O}_{\mathrm{s}}$ distance (corresponding to the second peak in Figure 10) with larger displacement steps ( 0.43 and $0.30 \AA)$. The system responds by opening both the anhydride and $\mathrm{O}-\mathrm{Mg}-\mathrm{O}$ bridges with essentially no change in average bond distances. On the other hand, the enhanced fluctuations of these parameters imply a weakening of the $\mathrm{P}-\mathrm{O}_{\mathrm{s}}-\mathrm{P}$ linkage. The related free energy change $(\Delta F=12.0 \mathrm{kcal} / \mathrm{mol}$ at $2.80 \AA)$ is moderate considering the lengths of the displacement, and the corresponding force implies that $\mathrm{Mg}^{2+}$ can be displaced farther with a relatively low cost. One possible mechanism for the ATP hydrolysis is then an event where a protein-active site, connected with $\mathrm{Mg}^{2+}$ via ligands, moves the electrophilic cation toward $\mathrm{O}_{\mathrm{s}}$, resulting in a cleavage of the terminal phosphate. There is theoretical evidence for an active role of $\mathrm{Mg}^{2+}$ in ribozyme. ${ }^{66}$

An important quantity describing the reactivity in biochemical systems is the equilibrium constant $\left(\mathrm{p} K_{\mathrm{a}}\right)$ related to the protonation (acidity) of the environment. $\mathrm{Mg}^{2+}$ affects the $\mathrm{p} K_{\mathrm{a}}$ value in ATP, and a completely deprotonated phosphate tail $\mathrm{Mg}(\mathrm{MTP})^{2-}$ is the dominant form under neutral conditions. ${ }^{15,16}$ The $\mathrm{Mg}$ cation also reduces $\mathrm{p} K_{\mathrm{a}}$ of the first $\mathrm{Mg}$ solvation shell by several units. ${ }^{46}$ During all of the above hydrolysis simulations, the octahedral solvation shell can make one direct hydrogen bond between a $\mathrm{Mg}$-coordinated $\mathrm{H}_{2} \mathrm{O}$ and an unsaturated $\mathrm{P}_{\beta}$ oxygen (see Figure 9). As the reactions proceed, this $\mathrm{H}$-bond becomes shorter and stronger, but no proton transfer occurs. The behavior probably arises from the steric change due to the $\mathrm{P}-\mathrm{O}_{\mathrm{s}}$ scission, not in the reduced $\mathrm{p} K_{\mathrm{a}}$.

\section{Discussion and Concluding Remarks}

ATP plays a crucial role in biology as a common energy currency of living cells, and ATP hydrolysis has different effects in different environments. In enzymes, the reaction free energy is very small $(1-2 \mathrm{kcal} / \mathrm{mol})$ and in some cases even positive, whereas a totally aqueous solution gives a strongly exergonic result $(-5$ to $-10 \mathrm{kcal} / \mathrm{mol}) .{ }^{9-11}$ The experimental conclusion is that the energy levels in the hydrolysis reaction depend on the water solvation of ATP, which can differ significantly on the surface of enzymes from those measured in pure water. The goal of the present study has been to give insight to the interaction between water and the $\mathrm{Mg}$-complexed triphosphate tail and to study the hydrolysis reaction in detail. The special role of $\mathrm{Mg}^{2+}$ has been emphasized. The density functional calculations are used with a variety of reaction coordinates. The related forces of constraint were recorded during short sequences of DF-based molecular dynamics, and their average values were used for the free energy determination.

Three different ATP hydrolysis reactions have been modeled: a dissociative reaction where the triphosphate is opened, an associative reaction where a water molecule reacts with the terminal $\mathrm{P}$ atom, and a combination of the two. The last reaction reduces to the dissociative one (involving $\mathrm{P}-\mathrm{O}_{\mathrm{s}}$ breaking), indicating that the dissociative mechanism is more favorable than a straightforward nucleophilic attack of $\mathrm{H}_{2} \mathrm{O}$. The overall barrier for the modified dissociative reaction is $35 \mathrm{kcal} / \mathrm{mol}$, where we assign $25 \mathrm{kcal} / \mathrm{mol}$ for the $\mathrm{P}-\mathrm{O}_{\mathrm{s}}$ bond cleavage, and the rest to the artificial stability the $\mathrm{PO}_{3}{ }^{-}$metaphosphate resulting from the small size of the sample and the short time scale of the simulation. The potential energy change upon hydrolysis is $4.2 \mathrm{kcal} / \mathrm{mol}$ for the last reaction, and it should be below zero when a complete solvation of the products is considered. The associative reaction with an activation energy of $39 \mathrm{kcal} / \mathrm{mol}$ is unlikely, but the reaction could proceed differently if a deprotonated $\mathrm{OH}^{-}$is considered as lytic water instead of $\mathrm{H}_{2} \mathrm{O}$. This is crucial in enzymes, where the $\mathrm{p} K_{\mathrm{a}}$ values differ significantly from those in bulk water. 
The catalytic role of $\mathrm{Mg}^{2+}$ has often been discussed, and both the gas-phase calculations ${ }^{28-30}$ and crystallization experiments ${ }^{22}$ of pyrophosphate have shown that the metal cation changes the properties of the $\mathrm{P}-\mathrm{O}_{\mathrm{s}}-\mathrm{P}$ linkage. This effect cannot be regarded as strain, because it changes neither the $\mathrm{P}-\mathrm{O}_{\mathrm{s}}-\mathrm{P}$ angle nor the torsional alignment of phosphates when compared with the Mg-free case. The ESP charges, for example, show that the elongation (and weakening) of the terminal $\mathrm{P}-\mathrm{O}_{\mathrm{s}}$ bond should be viewed as a property of the bidentate chelate formed. The octahedral $\mathrm{Mg}-\mathrm{O}$ coordination is preserved throughout complexation.

The preference for the dissociative reaction path has led us to consider ways to force the terminal phosphate cleavage. One is an active role for $\mathrm{Mg}^{2+}$, where the cation makes an electrophilic attack on a nearby phosphate oxygen. Our calculations suggest that it is relatively inexpensive to push $\mathrm{Mg}^{2+}$ toward the bridging oxygen, opening the $\mathrm{P}-\mathrm{O}_{\mathrm{s}}-\mathrm{P}$ angle and weakening the terminal $\mathrm{P}-\mathrm{O}_{\mathrm{s}}$ bond. This mechanism could occur in active sites of enzymes by structural changes that push $\mathrm{Mg}^{2+}$ toward the bridging $\mathrm{O}_{\mathrm{s}}$. Moreover, the electrophilic nature of $\mathrm{Mg}^{2+}$ increases as the water solvation is reduced, leading to a smaller activation energy of hydrolysis, as shown by the gasphase calculations of pyrophosphate hydrolysis. ${ }^{30}$

The density functional method provides a reliable description of atoms, molecular structure, and chemical reactions in the gas phase, properties of materials, etc., including a recent application to solution chemistry and related reactions..$^{45,47-51,69,70}$ The DF approach has advantages over classical force field methods, since it allows the breaking and formation of chemical bonds, and barrier heights and charge transfer phenomena are described reasonably well. However, even simple reactions in solution are very demanding from the DF point of view, since the presence of solvent molecules increases both the number of atoms (electrons) and degrees of freedom in the system, with rapidly growing demands on memory and simulation time. One must also retain control of all changes in the system during the reaction in order to determine the free energy changes. In the present case, $\mathrm{P}-\mathrm{O}_{\mathrm{w}}$ bond formation and proton transfer lead to missing (negative) contributions to the free energy. Finally, the determination of the optimum reaction path is a problem for all simulation methods, since the number of possibilities is very large. Nevertheless, the present calculations provide insight into the most likely mechanisms for ATP hydrolysis and provide an upper bound to the energy barrier. Algorithms for reaction path mapping exist, ${ }^{71,72}$ but their use for DF calculations is limited by the exhaustive sampling of configuration space required. We are optimistic that improvements in computational hardware and in numerical algorithms will change this picture.

Acknowledgment. The work was supported by the Bundesministerium für Bildung und Forschung (BMBF), Bonn, within the Kompetenzzentrum Materialsimulation, 03N6015). The DF calculations were performed on the Cray T3E computers in the Forschungszentrum Jülich with generous grants of CPU time from the Forschungszentrum and the John von Neumann Institute for Computing (NIC). J.A. thanks P. Carloni, A. Stirling, and M. Parrinello for valuable discussions.

\section{References and Notes}

(1) Devlin, T. M. Textbook of Biochemistry with Clinical Correlations, 4th ed.; Wiley-Liss, Inc.: New York, 1997.

(2) Vale, R. D.; Milligan, R. A. Science 2000, 288, 88.

(3) Otterbein, L. R.; Graceffa, P.; Dominguez, R. Science 2001, 293, 708 .

(4) O’Brien, M. C.; Flaherty, K. M.; McKay, D. B. J. Biol. Chem. 1996, 271,15874
(5) Abrahams, J. P.; Leslie, A. G. W.; Lutter, R.; Walker, J. E. Nature 1994, 370, 621 .

(6) Zhang, P.; Toyoshima, C.; Yonekura, K.; Green, N. M.; Stokes, D. L. Nature 1998, 392, 835 .

(7) Stock, D.; Leslie, A. G. W.; Walker, J. E. Science 1999, 286, 1700.

(8) Bauer, C. B.; Fonseca, M. V.; Holden, H. M.; Thoden, J. B.; Thompson, T. B.; Escalante-Semerena, J. C.; Rayment, I. Biochemistry 2001, 40,361 .

(9) George, P.; Witonsky, R. J.; Trachtman, M.; Wu, C.; Dorwart, W.; Richman, L.; Richman, W.; Shurayh, F.; Lentz, B. Biochim. Biophys. Acta 1970, 223,1

(10) Romero, P. J.; de Meis, L. J. Biol. Chem. 1989, 264, 7869.

(11) de Meis, L. Biochim. Biophys. Acta 1989, 973, 333.

(12) Alberty, R. A. Biochim. Biophys. Acta 1994, 1207, 1.

(13) Alberty, R. A. Biophys. Chem. 1998, 70, 109.

(14) Granot, J.; Fiat, D. J. Am. Chem. Soc. 1977, 99, 70.

(15) Sigel H.; Tribolet, R.; Malini-Balakrishnan R.; Martin, R. B. Inorg Chem. 1987, 26, 2149.

(16) Tribolet, R.; Sigel H. Eur. J. Biochem. 1988, 170, 617.

(17) Wang, P.; Oscarson, J. L.; Izatt, R. M.; Watt, G. D.; Larsen, C. D.

J. Sol. Chem. 1995, 24, 989.

(18) Wang, P.; Izatt, R. M.; Oscarson, J. L.; Gillespie, S. E. J. Phys. Chem. 1996, 100, 9556.

(19) Kennard, O.; Isaacs, N. W.; Motherwell, W. D. S.; Coppola, J. C.; Wampler, D. L.; Larson, A. C.; Watson, D. G. Proc. R. Soc. London A 1971, 325, 401.

(20) Larson, A. C. Acta Crystallogr. 1978, B34, 3601.

(21) Sugawara, Y.; Kamiya, N.; Iwasaki, H.; Ito, T.; Satow, Y. J. Am. Chem. Soc. 1991, 113, 5440.

(22) Souhassou, M.; Lecomte, C.; Blessing, R. H. Acta Crystallogr. 1992, $B 48,370$.

(23) Erragh, F.; Boukhari, A.; Holt, E. M. Acta Crystallogr. 1996, C52, 1867

(24) Urabe, H.; Sugawara, Y.; Kasuya, T. Phys. Rev. B 1995, 51, 5666.

(25) Fukui, K.; Imamura, A.; Nagata, C. Bull. Chem. Soc. Jpn. 1963 $36,1450$.

(26) Yoshikawa, K.; Shinohara, Y.; Terada, H.; Kato, S. Biophys. Chem. 1987, 27, 251

(27) Tajima, M.; Honda, M. J. Mol. Struct. 91, 228, 201.

(28) Ma, B.; Meredith, C.; Schaefer, H. F. J. Phys. Chem. 1995, 99 , 3815 .

(29) Colvin, M. E.; Evleth, E.; Akacem, Y. J. Am. Chem. Soc. 1996, $117,4357$.

(30) Saint-Martin, H.; Ruiz-Vicent, L. E.; Ramírez-Solís, A.; Ortega-

Blake, I. J. Am. Chem. Soc. 1996, 118, 12167.

(31) Johnson, J. R. T.; Panas, I. Chem. Phys. 2002, 276, 45.

(32) Kagawa, H.; Mori, K. J. Phys. Chem. B 1999, 103, 7346

(33) Okimoto, N.; Yamanaka, K.; Ueno, J.; Hata, M.; Hoshino, T.; Tsuda, M. Biophys. J. 2001, 81, 2786.

(34) Minehardt, T. J.; Marzari, N.; Cooke, R.; Pate, E.; Kollman, P. A., Car, R. Biophys. J. 2002, 82, 660.

(35) CPMD program version 3.4, Hutter, J. et al., Max-Planck-Institut für Festkörperforschung, Stuttgart, Germany, and IBM Research 19902001.

(36) Troullier, N.; Martins, J. L. Phys. Rev. B 1991, 43, 1993.

(37) Perdew, J. P.; Burke, K.; Ernzerhof, M. Phys. Rev. Lett. 1996, 77, 3865.

(38) Grein, F. Theochem. 2001, 536, 87.

(39) Markham, G. D.; Glusker, J. P.; Bock, C. W.; J. Phys. Chem. B 2002, 106, 5118 .

(40) Tuckerman, M., Laasonen, K.; Sprik, M.; Parrinello, M. J. Phys. Chem. 1995, 99, 5749.

(41) Tuckerman, M., Laasonen, K.; Sprik, M.; Parrinello, M. J. Chem. Phys. 1995, 103, 150

(42) Marx, D.; Tuckerman, M. E.; Hutter, J.; Parrinello, M. Nature 1999, 397, 601 .

(43) Trout, B. L.; Parrinello, M. Chem. Phys. Lett. 1998, 288, 343.

(44) Trout, B. L.; Parrinello, M. J. Phys. Chem. B 1999, 103, 7340.

(45) Sprik, M. Chem. Phys. 2000, 258, 139.

(46) Lightstone, F. C.; Schwegler, E.; Hood, R. Q.; Gygi, F.; Galli, G. Chem. Phys. Lett. 2001, 343, 549.

(47) Molteni, C.; Parrinello, M. J. Am. Chem. Soc. 1998, 120, 2168

(48) Alber, F.; Folkers, G.; Carloni, P. Theochem. 1999, 489, 237.

(49) Schwegler, E.; Galli, G.; Gygi, F. Chem. Phys. Lett. 2001, 342, 434.

(50) Meijer, E. J.; Sprik, M. J. Am. Chem. Soc. 1998, 120, 6345.

(51) Davies, J. E.; Doltsinis, N. L.; Kirby, A. J.; Roussev, C. D.; Sprik, M. J. Am. Chem. Soc. 2002, 124, 6594.

(52) Cornell, W. D.; Cieplak, P.; Bayly, C. I.; Gould, I. R.; Merz, K. M.; Ferguson, D. M.; Spellmeyer, D. C.; Fox, T.; Caldwell J. W.; Kollman, P. A. J. Am. Chem. Soc. 1995, 117, 5179 .

(53) Jorgensen, W. L.; Chandrasekhar, J.; Madura, J. D.; Impey, R. W.; Klein, M. L. Chem. Phys. 1983, 79, 926. 
(54) Xu, H.; Berne, B. J. J. Phys. Chem. B 2001, 105, 11929. 55. Tarek, M.; Tobias, D. J. Phys. Rev. Lett. 2002, 88, 138101.

(55) Tarek, M.; Tobias, D. J. Phys. Rev. Lett. 2002, 88, 138101.

(56) Obst, S.; Bradaczek, H. J. Phys. Chem. B 2001, 100, 15677.

(57) Mills, R. J. Phys. Chem. 1973, 77, 685.

(58) Price, W. S.; Ide, H.; Arata, Y. J. Phys. Chem. A 1999, 103, 448

(59) Mark, P.; Nilsson, L. J. Phys. Chem. A 2001, 105, 9954.

(60) Sprik, M.; Ciccotti, G. J. Chem. Phys. 1998, 109, 7737. We have applied the corresponding corrections for the reaction coordinate $Q_{\mathrm{PW}}$. The difference from eq 4 is negligible.

(61) Wang, X.-B.; Vorpagel, E. R.; Yang, X.; Wang, L.-S. J. Phys. Chem. A 2001, 105, 10468.

(62) The criteria for a hydrogen bond are $2.2 \AA$ for the $\mathrm{O} \cdots \mathrm{H}$ distance and $120^{\circ}$ for the $\mathrm{O}-\mathrm{H} \cdots \mathrm{O}$ angle.

(63) A vanishing force of constraint does not necessarily mean a completed reaction in a periodic system.
(64) This estimate is based on the difference between $\Delta E_{\mathrm{p}}$ and $\Delta F$ at the potential energy minimum.

(65) Agmon, N. Chem. Phys. Lett. 1995, 244, 456.

(66) Boero, M.; Terakura, K.; Tateno, M. J. Am. Chem. Soc. 2002, 124 , 8949.

(67) Whalley, E. Trans. Faraday Soc. 1957, 53, 1578.

(68) Saint-Martin, H.; Ortega-Blake, I.; Leś, A.; Adamowicz, L. Biochim. Biophys. Acta 1994, 1207, 12.

(69) Kirchner, B.; Stubbs, J.; Marx, D. Phys. Rev. Lett. 2002, 89, 215901.

(70) Curioni, A.; Sprik, M.; Andreoni, W.; Schiffer, H.; Hutter, J.; Parrinello, M. J. Am. Chem. Soc. 1997, 119, 7218.

(71) Bolhuis, P. G.; Chandler, D.; Dellago, C., Geissler, P. Annu. Rev. Phys. Chem. 2002, 59, 291.

(72) Laio, A.; Parrinello, M. Proc. Natl. Acad. Sci. U.S.A. 2002, 99, 12562. 